\title{
Características e Propriedades de Quitosanas Purificadas nas Formas Neutra, Acetato e Cloridrato
}

\author{
Roberta Signini, Sérgio P. Campana Filho \\ Instituto de Química de São Carlos, USP
}

Resumo: Quitosanas comercial e purificadas nas formas neutra, acetato e cloridrato foram caracterizadas e comparadas quanto a solubilidade, hidrofilicidade, morfologia de suas superfícies e cristalinidade. As amostras bruta e purificada na forma neutra apresentam características e propriedades semelhantes, mas as formas salinas, principalmente cloridratos de quitosana, são diferentes. As morfologias das superfícies da amostra comercial e das formas purificadas são semelhantes, mas cloridrato de quitosana obtido por liofilização apresenta poros que não são observados nas outras amostras. Quitosanas comercial e purificada na forma neutra não são solúveis em água, mas acetato de quitosana é parcialmente solúvel. Essas três formas de quitosana apresentam hidrofilicidades e cristalinidades semelhantes, mas nos casos dos cloridratos a presença de cargas e de contra-íons provenientes de um ácido forte aumenta a hidrofilicidade, confere hidrossolubilidade e altera significativamente as interações inter e intracadeias, modificando o empacotamento no estado sólido e resultando em importante decréscimo de cristalinidade. No caso de acetato de quitosana é observado que os cristalitos são menores, o que pode ser atribuído à protonação parcial dos grupos amino e à presença de ânions acetato.

Palavras-chave: Quitosana, purificação, acetato de quitosana, cloridrato de quitosana.

\section{Characteristics and Properties of Purified Chitosan in the Neutral, Acetate and Hydrochloride Forms}

Abstract: Commercial chitosan is purified in the neutral form and as chitosan acetate and chitosan hydrochloride. These samples were characterized and compared with respect to solubility, hydrophilicity, surface's morphology and crystallinity. Commercial chitosan and its neutral purified form present similar characteristics and properties but the saline purified forms, mainly the chitosan hydrochlorides, are quite different from them. The surface morphologies of the former samples are similar but that of the lyophilized chitosan hydrochloride presents pores which are not observed in the other samples. Commercial chitosan and its neutral purified form are not soluble in pure water but chitosan acetate is partially soluble. These samples present similar hydrophylicities and crystallinities but in the cases of the chitosan hydrochlorides the presence of charges and of counter ions from a strong acid enhances the hydrophilicity, promotes solubility in water and significantly alters the interactions inter and intrachains, modifying the packing in the solid state and drastically reducing the crystallinity. In the case of chitosan acetate it is observed that the crystallites are smaller probably due to the partial protonation of amine groups and to the presence of acetate anions.

Keywords: Chitosan, purification, chitosan acetate, chitosan hydrochloride.

\section{Introdução}

As propriedades de polieletrólitos derivados de polissacarídeos, principalmente daqueles obtidos por modificações químicas que visam introduzir os grupos carregados, e a sua exploração em aplicações dependem fortemente das suas características estruturais e comportamento físico-químico ${ }^{[1]}$. A caracterização

Autor para correspondência: Sérgio P. Campana Filho, Instituto de Química de São Carlos, USP-SP;Av. do Trabalhador Sancarlense,400, CEP: 13560970, São Carlos, SP. E-mail: scampana@iqsc.sc.usp.br 
desses polímeros, por sua vez, deve ser realizada com amostras devidamente purificadas, ou o estabelecimento das relações entre características estruturais, propriedades e comportamentos será muito dificultado. Nesse sentido, materiais insolúveis ou fortemente agregados devem ser excluídos da amostra a ser caracterizada, principalmente quando propriedades de soluções diluídas são investigadas e correlacionadas com suas características estruturais ${ }^{[2]}$.

A ocorrência de agregação e a ausência de solubilidade se devem ao tipo de processo geralmente empregado para a obtenção desses polímeros, que gera produtos não-uniformes ${ }^{[1]}$, mas também são devidas à natureza associativa dos polissacarídeos ${ }^{[3]}$. Este é o caso de carboximetilcelulose e de quitosana, obtidos por derivatização de celulose ${ }^{[4]}$ e por desacetilação de quitina ${ }^{[5]}$, respectivamente. Em ambos os casos, os polissacarídeos de partida são suspensos no meio reacional, não-solvente para os polímeros, e submetidos a modificações químicas através de reações heterogêneas. De fato, os agentes modificadores estão dissolvidos nos meios em que essas reações ocorrem, mas não têm plena acessibilidade aos sítios reativos das cadeias poliméricas, que apenas se separam limitadamente umas das outras, mas permanecem insolúveis durante as reações, pois se associam fortemente através de numerosas ligações hidrogênio ${ }^{[6,7]}$. Nas regiões amorfas, nas quais a acessibilidade aos sítios reativos é maior, álcali-celulose $\mathrm{e}^{[6]} \mathrm{e}$ álcaliquitina são formados e as reações são consideradas pseudo-homogêneas ${ }^{[8]}$. As regiões cristalinas não são completamente acessíveis e as superfícies dos cristalitos são as mais sujeitas às reações ${ }^{[6,8]}$.

Assim, a desacetilação de quitina e a carboximetilação de celulose em solução aquosa de $\mathrm{NaOH}$ se processam heterogeneamente e geram produtos cujas cadeias são formadas por seqüências de unidades modificadas quimicamente e unidades que não sofreram a modificação química desejada ${ }^{[6-8]}$. As propriedades de quitosana e carboximetilcelulose, incluindo solubilidade, dependem fortemente do grau médio de carga dos polímeros e de sua distribuição ao longo das cadeias.

As carboximetilceluloses são preparadas como sais de sódio que são solúveis em água se o grau médio de substituição for superior a $0,5^{[4,6]}$, mas os produtos menos substituídos formam estruturas agregadas e materiais insolúveis ${ }^{[3]}$. No caso da desacetilação heterogênea de quitina, as quitosanas produzidas também possuem distribuição em blocos, constituídos por unidades acetiladas e desacetiladas, e só podem ser solubilizadas em soluções diluídas de ácidos ${ }^{[7]}$. Entretanto, se quitosanas são tratadas em solução de metanol/ ácido acético com anidrido acético, o polissacarídeo é dissolvido nesse meio e reage homogeneamente para gerar produtos com distribuição aleatória de unidades acetiladas e desacetiladas, hidrossolúveis quando o grau de acetilação é de $50 \%{ }^{[9]}$.

Tais comportamentos quanto à solubilidade podem ser atribuídos à preservação parcial de domínios em que as interações associativas predominavam nas cadeias dos polissacarídeos de partida, o que favorece a agregação e diminui a solubilidade dos seus derivados obtidos heterogeneamente.

Com respeito ao estabelecimento de correlações entre estruturas e propriedades de polissacarídeos polieletrolíticos é também muito importante que na amostra purificada apenas um tipo de contra-íon esteja presente ${ }^{[2]}$. Dessa maneira, o comportamento em função do ambiente (acidez, força iônica e presença de co-íons/contra-íons, temperatura) em que o polieletrólito está dissolvido pode ser mais bem estudado e compreendido.

De maneira geral, os polieletrólitos polianiônicos, i.e., aqueles portadores de sítios iônicos que desenvolvem cargas negativas quando dissolvidos nos solventes aquosos apropriados, são purificados através de procedimentos que envolvem as seguintes etapas seqüenciais: i) dissolução em meio aquoso de força iônica controlada; ii) filtração; iii) precipitação por adição de não-solvente e iv) lavagens e secagem. Polieletrólitos assim purificados são formas salinas hidrofílicas e, em geral, são solúveis em água à temperatura ambiente. A natureza do sal empregado para controlar a força iônica na etapa de dissolução define previamente o tipo de contra-íon que estará presente na amostra purificada. De fato, para assegurar que apenas um contra-íon estará presente após a purificação, um grande excesso molar de sal é adicionado em relação à quantidade de sítios iônicos do polieletrólito. Uma vez que insolúveis e agregados são eliminados, por filtração ou por centrifugação, a solubilidade do polieletrólito no meio é progressivamente diminuída através da adição de um nãosolvente o qual, em geral, é um álcool ou uma cetona de cadeia curta. Em função das concentrações de polímero e de sal adicionado, a precipitação do polímero ocorrerá quando um teor crítico de não- 
solvente tiver sido atingido, devido a sua pobre solubilidade nesse meio. O polieletrólito, precipitado na forma salina, é então exaustivamente lavado para eliminar o excesso de sal e submetido a secagem. Dessa maneira, polieletrólitos polianiônicos portadores de grupos carboxílicos, tais como carboximetilcelulose, são purificados como sais de sódio hidrossolúveis. Alternativamente, a solução aquosa do polieletrólito pode ser submetida à diálise contra solução contendo um grande excesso do contra-íon desejado e o polímero na forma salina é isolado por liofilização.

A quitosana, um polieletrólito catiônico quando dissolvido no meio apropriado, é geralmente purificado na forma neutra, obtida após dissolução do polímero em solução aquosa diluída de ácido acético, filtração e adição de álcali aquoso até provocar sua precipitação. Sais purificados de quitosana podem ser obtidos de maneira semelhante à descrita para polieletrólitos aniônicos, resultando em materiais hidrossolúveis, os quais são largamente aplicados, por exemplo, nas indústrias farmacêutica e cosmética ${ }^{[10,11]}$.

Neste trabalho são empregadas diferentes metodologias de purificação à quitosana comercial para a obtenção da amostra na forma neutra e como cloridrato e acetato de quitosana. Características estruturais e morfológicas e propriedades das amostras purificadas em diferentes formas são comparadas.

\section{Experimental}

\section{Purificações de quitosana}

A quitosana comercial bruta (Fluka-Biochimika, designada amostra $A_{B}$ ) foi empregada neste trabalho e sua purificação em diferentes formas foi realizada conforme descrito a seguir.

Forma neutra: $1.0 \mathrm{~g}$ de quitosana foi disperso em $300 \mathrm{~mL}$ de ácido acético diluído (1\%), e a suspensão foi mantida sob agitação constante durante aproximadamente $24 \mathrm{~h}$. A solução resultante foi seqüencialmente filtrada sob pressão positiva através de membranas de porosidades $5 \mu \mathrm{m}, 0,8 \mu \mathrm{m}$ e $0,45 \mu \mathrm{m}$. À solução filtrada foi adicionado, aos poucos, hidróxido de amônio concentrado até a ocorrência de precipitação. Em seguida o precipitado foi transferido para um filtro e lavado com água até a neutralidade, em seguida com metanol e seco à temperatura ambiente. A amostra de quitosana purificada desta maneira foi denominada amostra $A_{N}$.
Acetato de quitosana (forma precipitada): 1,0 g de quitosana foi disperso em $150 \mathrm{~mL}$ de ácido acético diluído (1\%), e a suspensão foi mantida sob agitação constante durante aproximadamente $24 \mathrm{~h}$. À solução resultante foram adicionados $150 \mathrm{~mL}$ de acetato de sódio $0,2 \mathrm{~mol} / \mathrm{L}$ e, em seguida, foi seqüencialmente filtrada sob pressão positiva através de membranas de porosidades $5 \mu \mathrm{m}, 0,8 \mu \mathrm{m}$ e $0,45 \mu \mathrm{m}$. À solução filtrada foi adicionado, aos poucos, etanol absoluto até a ocorrência de precipitação e, em seguida, a suspensão foi centrifugada por $15 \mathrm{~min}$. (10500 rpm e temperatura de $25^{\circ} \mathrm{C}$ ). Após a retirada do sobrenadante, etanol $80 \%$ foi adicionado à suspensão, que foi agitada por aproximadamente 5 min. e então centrifugada. Este procedimento foi repetido empregando misturas etanol/água com teores crescentes de álcool e, na última etapa, metanol absoluto foi empregado. A forma purificada de acetato de quitosana, denominada amostra $\mathrm{A}_{\mathrm{AP}}$, foi transferida para uma placa de Petri e seca à temperatura ambiente.

Cloridrato de quitosana (forma precipitada): 1,0 $\mathrm{g}$ de quitosana foi disperso em $150 \mathrm{~mL}$ de ácido clorídrico $(0,05 \mathrm{~mol} / \mathrm{L})$, e a suspensão foi mantida sob agitação constante durante aproximadamente $24 \mathrm{~h}$. À solução resultante foram adicionados $150 \mathrm{~mL}$ de $\mathrm{NaCl}$ ( $0,2 \mathrm{~mol} / \mathrm{L})$ que, em seguida, foi sequencialmente filtrada sob pressão positiva através de membranas de porosidades $5 \mu \mathrm{m}, 0,8 \mu \mathrm{m}$ e $0,45 \mu \mathrm{m}$. À solução filtrada foi adicionado, aos poucos, etanol até a ocorrência de precipitação e, em seguida, a suspensão foi centrifugada por $15 \mathrm{~min}$. (10500 rpm e temperatura de $25^{\circ} \mathrm{C}$ ). Após a retirada do sobrenadante, etanol $80 \%$ foi adicionado à suspensão, que foi agitada por aproximadamente 5 min. e então centrifugada. Este procedimento foi repetido empregando misturas etanol/água com teores crescentes de álcool e, na última etapa, foi empregado metanol absoluto. Esta forma purificada de cloridrato de quitosana, denominada amostra $\mathrm{A}_{\mathrm{CP}}$, foi transferida para uma placa de Petri e seca à temperatura ambiente.

Cloridrato de quitosana (forma liofilizada): 1,0 g de quitosana foi disperso em $150 \mathrm{~mL}$ de ácido acético (1\%) e a suspensão foi mantida sob agitação constante durante aproximadamente $24 \mathrm{~h}$. A solução resultante foi seqüencialmente filtrada sob pressão positiva através de membranas de porosidades $8,0 \mu \mathrm{m}$, $5,0 \mu \mathrm{m}, 0,8 \mu \mathrm{m}$ e $0,45 \mu \mathrm{m}$. Em seguida foi realizada diálise, empregando membrana de celofane com limite de exclusão $12000-14000 \mathrm{~g} / \mathrm{mol}$, por três dias contra solução aquosa de $\mathrm{NaCl}$ 0,2 mol/L e dois dias contra água destilada e desionizada. Após a diálise a 
amostra de cloridrato de quitosana foi liofilizada, sendo denominada amostra $\mathrm{A}_{\mathrm{CL}}$.

\section{Caracterizações das amostras}

As amostras de quitosana purificadas em diferentes formas foram caracterizadas quanto a grau médio

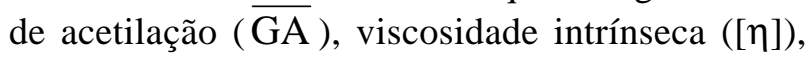
cristalinidade, caráter hidrofílico e morfologia conforme os procedimentos descritos a seguir.

Grau médio de acetilação e Viscosidade intrínseca

Os valores de graus médio de acetilação, $(\overline{\mathrm{GA}})$, e de viscosidade intrínseca, [ $\eta$ ], das quitosanas purificadas foram determinados por espectroscopia de ressonância magnética nuclear de próton ( ${ }^{1} \mathrm{H}$ r.m.n.) e viscosimetria capilar, respectivamente, conforme descrito na literatura ${ }^{[12,13]}$.

\section{Difração de raios-X}

As amostras de quitosana foram analisadas através de medidas de difração de raios-X, realizadas em difratômetro Rigaku com tubo de cobre $(\lambda=1,54 \AA)$, empregando voltagem de $40 \mathrm{kV}$ e corrente de $40 \mathrm{~mA}$. As medidas foram realizadas no intervalo $3^{\circ}<2 \theta<50^{\circ}$, com varredura em etapas de $0,02^{\circ}$ e velocidade de varredura de $1^{\circ} \mathrm{C} / \mathrm{min}$.

\section{Termogravimetria}

Nas curvas termogravimétricas, visam determinar os graus de umidade e os teores de cinzas das amostras, foi utilizado o módulo termogravimétrico Shimadzu modelo TGA-50. As análises foram realizadas em atmosfera de ar sintético (fluxo de $20 \mathrm{~mL} /$ min) no intervalo $20^{\circ} \mathrm{C}<\mathrm{T}<700^{\circ} \mathrm{C}$ e taxa de aquecimento de $10^{\circ} \mathrm{C} / \mathrm{min}$, e as amostras analisadas (4-6mg) foram previamente condicionadas em dessecador com umidade relativa de $96 \%$ durante 20 dias. Os graus de umidade das amostras foram determinados como as perdas de massa ocorridas enquanto estas eram aquecidas desde a temperatura ambiente até $180{ }^{\circ} \mathrm{C}$ e os correspondentes teores de cinzas foram calculados a partir dos valores de massa residual após aquecimento à $700^{\circ} \mathrm{C}$.

Microscopia eletrônica de varredura

As amostras de quitosana foram analisadas em microscópio eletrônico de varredura digital modelo LEO-440, empregando corrente de 500pA e potên- cia $15 \mathrm{kV}$. Para essas análises as amostras foram fixadas no porta-amostra sobre fita adesiva de carbono e recobertas com uma fina camada (20nm) de ouro.

\section{Resultados e Discussão}

Os procedimentos empregados neste trabalho se mostraram apropriados à purificação de quitosana, pois seus resultados foram reprodutíveis e seus rendimentos semelhantes, permitindo a recuperação de $85-95 \%$ da massa inicial. Tais procedimentos, entretanto, resultaram em quitosanas distintas quanto à solubilidade, hidrofilicidade e características morfológicas. As amostras purificadas como cloridrato por precipitação (amostra $\mathrm{A}_{\mathrm{CP}}$ ), acetato por precipitação (amostra $\mathrm{A}_{\mathrm{AP}}$ ) e na forma neutra (amostra $A_{N}$ ) são pós marrons-claros enquanto a forma liofilizada de cloridrato de quitosana (amostra $\mathrm{A}_{\mathrm{CL}}$ ) é constituída por flocos brancos. Todas as amostras purificadas são solúveis em solução diluída de ácido acético, mas as quitosanas obtidas como cloridratos (amostras $\mathrm{A}_{\mathrm{CP}}$ e $\mathrm{A}_{\mathrm{CL}}$ ) também são completamente solúveis em água, enquanto acetato de quitosana é apenas parcialmente solúvel nesse meio. Este comportamento das formas salinas é esperado, em função de sua elevada hidrofilicidade, e $\mathrm{o}$ fato de a forma acetato de quitosana (amostra $\mathrm{A}_{\mathrm{AP}}$ ) ser apenas parcialmente solúvel em água deve ser atribuído à protonação incompleta dos grupos amino pelas moléculas de ácido acético, um ácido considerado fraco. De fato, a hidrofilicidade dessa amostra se assemelha mais àquelas de quitosana bruta e purificada na forma neutra do que às correspondentes a cloridratos de quitosana, que são formas mais hidrofílicas (Tabela 1). Através desses dados também é constatado que, independentemente de se tratar de quitosana bruta ou purificada por qualquer dos procedimentos descritos, os teores de cinzas residuais são baixos.

Tabela 1. Graus de umidade (GU) e teores de cinzas residuais (CR) de quitosana bruta e formas purificadas.

\begin{tabular}{ccc}
\hline Amostra & \%GU & \% CR \\
\hline $\mathrm{A}_{\mathrm{B}}$ & $20,2 \pm 1,4$ & $2,1 \pm 0,6$ \\
$\mathrm{~A}_{\mathrm{N}}$ & $23,3 \pm 0,6$ & $1,9 \pm 0,1$ \\
$\mathrm{~A}_{\mathrm{AP}}$ & $23,8 \pm 0,4$ & $1,4 \pm 0,0$ \\
$\mathrm{~A}_{\mathrm{CL}}$ & $32,7 \pm 4,4$ & $1,8 \pm 0,7$ \\
$\mathrm{~A}_{\mathrm{CP}}$ & $36,4 \pm 2,4$ & $1,8 \pm 0,7$ \\
\hline
\end{tabular}

a) valores correspondentes a médias de, ao menos, duas determinações independentes 


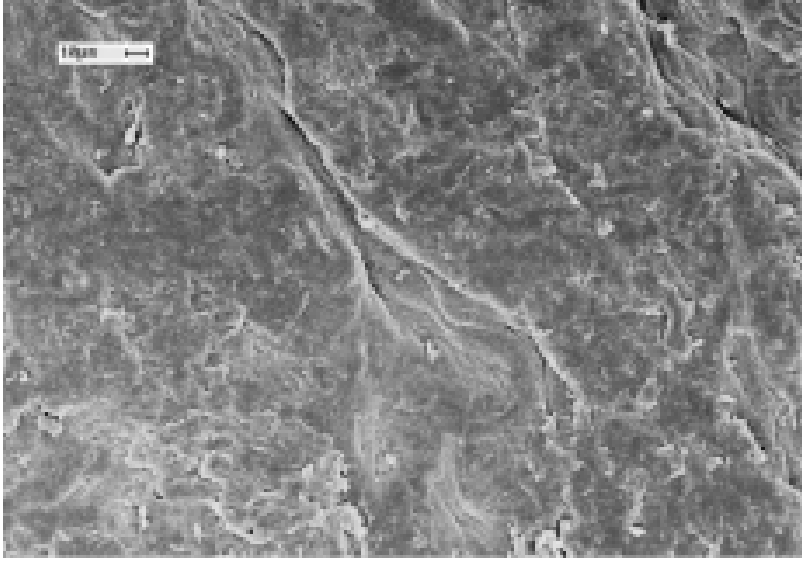

(a)

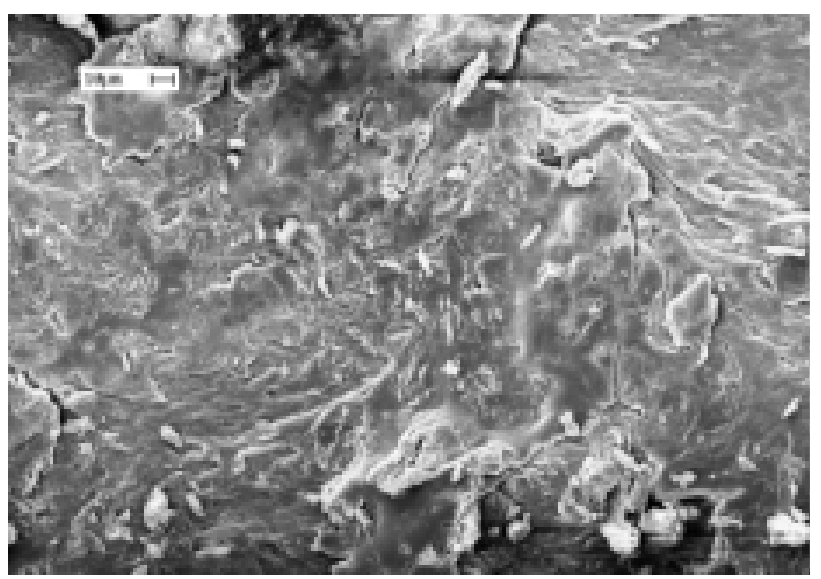

(c)

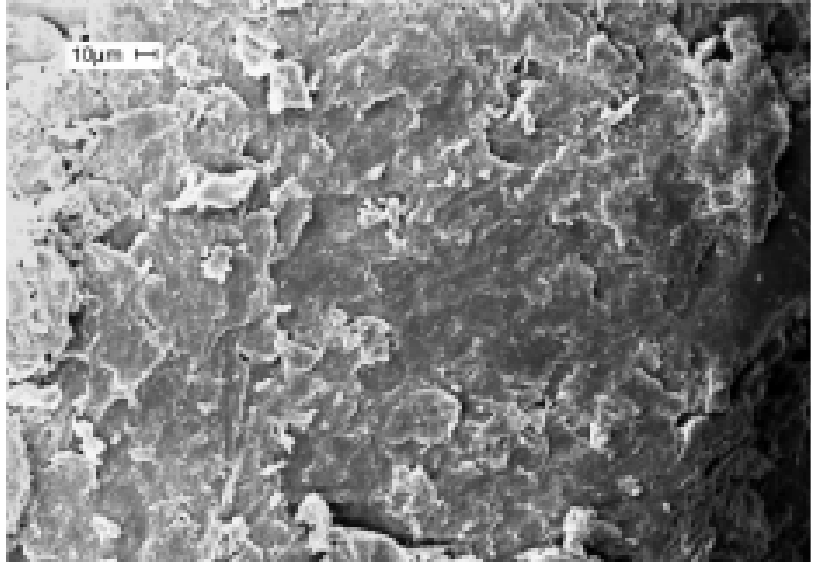

(b)

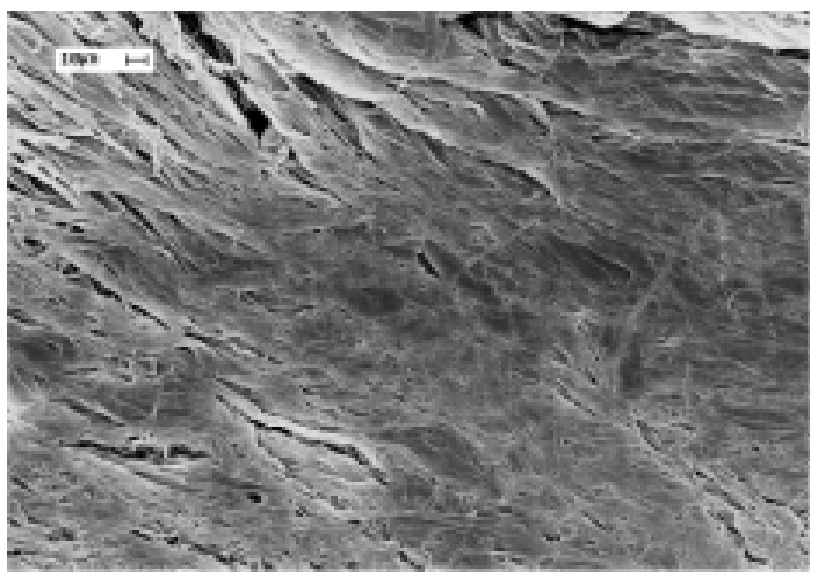

(d)

Figura 1. Micrografias das superfícies de quitosana (aumento de 1000x): a) amostra $A_{B} ; b$ ) amostra $\left.A_{N} ; c\right)$ amostra $A_{C P} ; d$ ) amostra $A_{C L}$

A capacidade desses polímeros reter umidade é determinada pela presença, quantidade e natureza de grupos hidrofílicos (carregados ou não) e, também, pela cristalinidade e características morfológicas das amostras $^{[14-16]}$. Desse ponto de vista, as amostras de quitosana bruta e purificada na forma neutra (e também acetato de quitosana) se assemelham, mas são diferentes de cloridrato de quitosana. De fato, as superfícies de todas essas amostras se apresentam rugosas, irregulares e destituídas de um padrão de ordenamento reconhecível mas as amostras purificadas como cloridratos de quitosana (principalmente a amostra $A_{C L}$, que se apresenta como flocos) apresenta uma estrutura porosa (Figura 1), o que também pode explicar, em parte, as maiores capacidades de reter água exibidas por estas últimas.

Os difratogramas das amostras de quitosana também revelam semelhanças entre a quitosana comercial e as amostras purificadas na forma neutra e como acetato de quitosana (Figura 2a), e mostram que es- sas adotam um arranjo muito diferente daquele assumido pelos cloridratos de quitosana (Figura $2 b$ ).

De fato, os difratogramas das amostras $A_{B}$ e $A_{N}$ estão quase que perfeitamente superpostos, exceto pelo pequeno deslocamento do sinal mais intenso,em $2020^{\circ}$, observado no difratograma da amostra $A_{N}$, indicando que no processo de purificação na forma neutra (que envolve dissolução seguida de precipitação por neutralização) as cadeias macromoleculares retêm a "memória" do arranjo que adotavam na amostra de partida. Tal hipótese parece razoável pois nesse processo de purificação são excluídos, essencialmente, materiais insolúveis que correspondem à cadeias de quitina pouco desacetiladas e de massa molar elevada, os sítios responsáveis pelo estabelecimento de ligações hidrogênio não são modificados e não são adicionadas cargas nem contra-íons que alterem as interações intra e intercadeias (principalmente ligações hidrogênio) e o seu empacotamento. No difratograma da amostra de acetato de quitosana (amostra $\mathrm{A}_{\mathrm{CP}}$ ) é claramente observado que o 


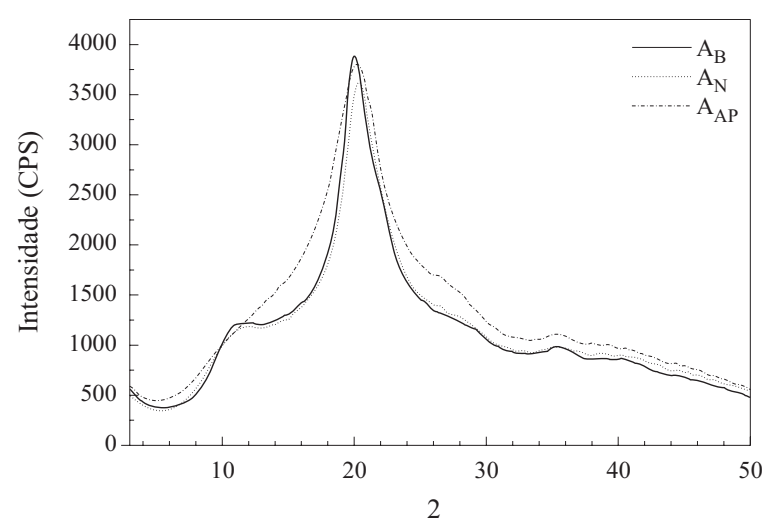

(a)

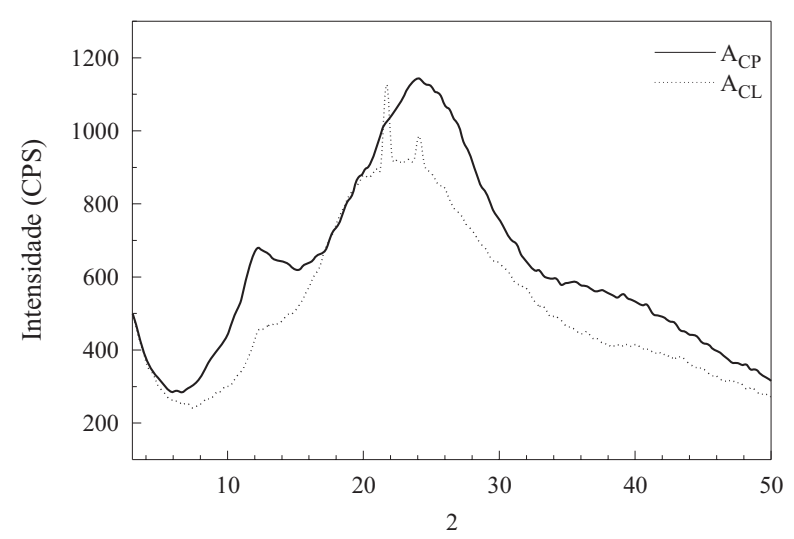

(b)

Figura 2. Difratogramas de quitosana: a) amostras $A_{B}, A_{N}$ e $A_{C P}$ e b) $\operatorname{amostras} \mathrm{A}_{\mathrm{CP}}$ e $\mathrm{A}_{\mathrm{CL}}$.

sinal mais intenso, em $2 \theta \cong 20^{\circ}$, também não sofreu deslocamento ou diminuição de intensidade significativos, mas é muito mais largo que o observado nos difratogramas das amostras $\mathrm{A}_{\mathrm{B}}$ e $\mathrm{A}_{\mathrm{N}}$. Por outro lado, os difratogramas de cloridratos de quitosana (amostras $\mathrm{A}_{\mathrm{CP}}$ e $\mathrm{A}_{\mathrm{CL}}$ ) revelam a ocorrência de importantes deslocamento e alargamento dos sinais e também de significativa redução de intensidade.

Os índices de cristalinidade, ou graus de ordenamento, de polímeros podem ser determinados a partir de análises de difração de raios- $\mathrm{X}^{[17]}$ e metodologias específicas têm sido desenvolvidas para serem aplicadas à celulose ${ }^{[18]}$, quitina e quitosana ${ }^{[8,19]}$. Neste trabalho foi aplicada a metodologia apropriada à determinação dos índices de cristalinidade de quitina e quitosana ${ }^{[8,19]}$ que foram calculados através da expressão abaixo:

$$
\% \mathrm{I}_{\mathrm{CR}}=\left(\mathrm{I}_{\mathrm{C}}-\mathrm{I}_{\mathrm{A}} / \mathrm{I}_{\mathrm{C}}\right) 100
$$

onde: \% $\mathrm{I}_{\mathrm{CR}}$ é o índice de cristalinidade; $\mathrm{I}_{\mathrm{C}}$ e $\mathrm{I}_{\mathrm{A}}$ são as intensidades difratadas relativas às regiões cristalinas $\left(2 \theta \cong 20^{\circ}\right)$ e amorfas $\left(2 \theta \cong 12^{\circ}\right)$, respectivamente.
Tabela 2. Valores de índices de cristalinidade $\left(\mathrm{I}_{\mathrm{CR}}\right)$, dimensão média dos cristalitos $\left(\mathrm{D}_{\text {ap }}\right)$, graus médios de acetilação $(\overline{G A})$, viscosidades intrínsecas $([\eta])$ e massas molares médias viscosimétricas $\left(\overline{M_{v}}\right)$ de quitosanas comercial e formas purificadas.

\begin{tabular}{|c|c|c|c|c|c|}
\hline Amostra & $\% \mathrm{I}_{\mathrm{CR}}$ & $\mathbf{D}_{\text {ap }}(\AA)$ & $\% \overline{G A}$ & {$[\eta](\mathrm{mL} / \mathrm{g}]$} & $\bar{M}_{v} \times 10^{4}(\mathrm{~g} / \mathrm{mol})$ \\
\hline$A_{B}$ & 68,5 & 17,9 & n.d. & n.d. & n.d. \\
\hline$A_{N}$ & 67,7 & 16,5 & 26,0 & 689 & 16,7 \\
\hline $\mathrm{A}_{\mathrm{AP}}$ & 64,1 & 10,6 & 22,0 & 725 & 17,2 \\
\hline $\mathrm{A}_{\mathrm{CL}}$ & n.d. & n.d. & 23,0 & 613 & 14,3 \\
\hline $\mathrm{A}_{\mathrm{CP}}$ & n.d. & n.d. & 23,0 & 671 & 16,1 \\
\hline
\end{tabular}

Esse tratamento não foi aplicado aos difratogramas das amostras $\mathrm{A}_{\mathrm{CP}}$ e $\mathrm{A}_{\mathrm{CL}}$, que apresentam sinais muito menos intensos e são típicos de quitosanas amorfas $^{[19]}$, cuja ausência de ordenamento deve ser atribuído à presença de cargas positivas (devido à protonação dos grupos amino) nas cadeias dessas amostras e de seus respectivos contra-íons. Entretanto, o emprego da expressão (1) nos casos das amostras $A_{B}, A_{N}$ e $A_{A P}$ revela que essas são bastante semelhantes quanto a cristalinidade (Tabela 2).

Como esperado, devido à semelhança existente entre seus difratogramas, as amostras bruta $\left(A_{B}\right)$ e purificada na forma neutra $\left(A_{N}\right)$ possuem índices de cristalinidade muito próximos e um pouco superiores ao de acetato de quitosana. Segundo a literatu$\mathrm{ra}^{[14,19]}$, a dimensão média dos cristalitos na direção perpendicular ao plano [110] é inversamente proporcional à largura do sinal correspondente às regiões cristalinas $\left(2 \theta \cong 20^{\circ}\right)$ no ponto em que a sua intensidade é a metade da intensidade máxima.

$$
\mathrm{D}_{\text {ap }}=\mathrm{K} \lambda / \beta_{0} \cos \theta
$$

onde: $\mathrm{D}_{\text {ap }}$ é a dimensão média dos cristalitos $(\AA)$; $\mathrm{K}$ é uma constante; $\lambda$ é o comprimento de onda $(\AA)$ da radiação empregada; $\beta_{0}$ (radianos) é a largura do sinal devido às regiões cristalinas no ponto de média intensidade e $\theta$ (radianos) é a metade do ângulo de Bragg correspondente ao sinal mais intenso.

O emprego da expressão (2) mostra que a purificação na forma neutra resultou em pequeno decrésci-

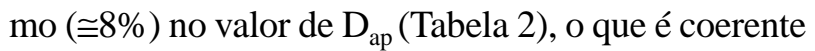
com a tese colocada anteriormente segundo a qual esse processo não altera significativamente as interações inter e intracadeias e nem modifica seu empacotamento. Por outro lado, no caso da amostra $\mathrm{A}_{\mathrm{AP}}$ é observada uma redução muito mais importante $(\cong 40 \%)$, o que sustenta a proposta que a presença de cargas e de 
contra-íons dificulta as interações inter e intracadeias, que então já não podem se empacotar tão densamente, e favorece o processo de solubilização.

Quanto aos graus médios de acetilação, viscosidades intrínsecas e massas molares médias viscosimétricas, independentemente do procedimento empregado para purificação da amostra comercial, as quitosanas purificadas são muito semelhantes, o que sustenta a afirmação que todos os procedimentos empregados são adequados à purificação de quitosana.

\section{Conclusões}

Em função do procedimento empregado, quitosanas com elevado grau de pureza e com propriedades e comportamentos distintos são obtidas. A comparação entre as diferentes formas purificadas de quitosana mostra que, nos casos de cloridratos de quitosana, a presença de cargas e de contra-íons altera drasticamente as interações inter e intracadeias, modificando o seu arranjo no estado sólido, aumentando sua hidrofilicidade e conferindo solubilidade em água sem a necessidade da adição de ácido para promover a completa solubilização do polissacarídeo. A amostra purificada como acetato de quitosana não apresenta as mesmas propriedades, o que pode ser atribuído ao caráter de ácido fraco do ácido empregado em sua obtenção.

\section{Agradecimentos}

Os autores agradecem à FAPESP e ao CNPq pelo apoio financeiro outorgado durante a realização deste trabalho.

\section{Referências Bibliográficas}

1. Yalpani, M. - "Polysaccharides: Synthesis, Modifications and Structure/Property Relations", Elsevier, Amsterdam (1988).

2. Rinaudo, M. - J. Appl. Polym. Sci.: Appl. Polym. Symp., 52, p.11 (1993).

3. Schulz, L.; Burchard, W.; Dönges, R. - "Evidence of supramolecular structures of cellulose derivatives in solution", in: Cellulose Derivatives: modification, characterization, and nanostructures, cap.16, p.218238; Thomas J. Heinze \& Wolfang G. Glasser eds.; American Chemical Society, Washington (1996).
4. Juste, K. E.; Majewicz, T. G. - "Encyclopedia of Polymer Science and Engineering" 2.ed., v.3, p.226-269; Kroschwitz, J. I. ed.; New York, John Wiley \& Sons (1985).

5. Hirano, S. - "Ullmann's Encyclopedia of Industrial Chemistry"; Gerhartz,W. (ed) vol. A6, p.231-232, $6^{\text {th }}$ edition, New York, VCH (1986).

6. Fengel, D. \& Wegener, G. - "Wood: Chemistry, Ultrastructure, Reactions", Walter de Gruyter \& Co., Berlin (1984).

7. Roberts, G. A. F. - "Chitin Chemistry", The Macmillan Press Ltd, London (1992).

8. Li, J.; Revol, J. -F. \& Marchessault, R. H. - J. Appl. Polym. Sci. 65(2), p.373 (1997).

9. Kurita, K.; Kamiya, M. \& Nishimura, S. I. - Carbohydr. Polym. 16, p. 83 (1991).

10. Goosen, M. F. A. - "Applications of Chitin and Chitosan", Technomic Publishing Company, Inc., Lancaster (1997).

11. Campana Filho, S. P. \& Desbrières, J. - "Chitin, Chitosan and Derivatives", in: Natural Polymers and Agrofibers Composites, cap. 3, E. Frollini; A. Leão \& L. H. C. Mattoso (eds.), EMBRAPA Instrumentação Agropecuária, São Paulo (2000).

12. Signini, R. \& Campana Filho, S. P. - Polímeros, Ciência e Tecnologia, p.63 (1999).

13. Signini, R. \& Campana Filho, S. P. - Polym. Bull. 42, p. 159 (1999).

14. Berthold, J.; Desbrières, J.; Rinaudo, M. \& Salmén, L. - Polymer 35(23), p. 5729 (1994).

15. Fringant, C.; Desbrières, J.; Milas, M.; Rinaudo, M.; Joly, C. \& Escoubes, M. - Int. J. Biol. Macromol. 18 , p. 281 (1996).

16. Hatakeyama, H. \& Hatakeyama, T. - Thermoch. Acta 308 , p. 3 (1998).

17. Alexander, L. E. - "Degree of Crystallinity of Polymers", in: X-Ray Diffraction Methods in Polymer Science, cap. 3, John Wiley \& Sons Inc., Malabar (1985).

18. Hermans, P. H. \& Weidinger, A - J. Appl. Phys. 19, p. 491 (1949).

19. Focher, B.; Beltrame, P. L.; Naggi, A.; Torri, G. Carbohydr. Polym. 12, p. 405 (1990).

Recebido: $24 / 04 / 01$

Aprovado: 13/06/01 